\title{
INDICADORES ECONÔMICOS
}

\begin{tabular}{|c|c|c|c|c|c|c|c|}
\hline \multirow{2}{*}{\multicolumn{2}{|c|}{ Período }} & \multicolumn{3}{|c|}{ IPC/FIPE } & \multicolumn{3}{|c|}{ IPCA } \\
\hline & & Mensal & No ano & $\begin{array}{l}\text { Em } 12 \\
\text { meses }\end{array}$ & Mensal & No ano & $\begin{array}{l}\text { Em } 12 \\
\text { meses }\end{array}$ \\
\hline \multirow{12}{*}{2010} & Jan. & 1,34 & 1,34 & 4,56 & 0,75 & 0,75 & 4,59 \\
\hline & Fev. & 0,74 & 2,09 & 5,05 & 0,78 & 1,54 & 4,83 \\
\hline & Mar. & 0,34 & 2,44 & 4,98 & 0,52 & 2,06 & 5,17 \\
\hline & Abr. & 0,39 & 2,84 & 5,07 & 0,57 & 2,65 & 5,26 \\
\hline & Mai. & 0,22 & 3,06 & 4,95 & 0,43 & 3,09 & 5,22 \\
\hline & Jun. & 0,04 & 3,10 & 4,86 & 0,00 & 3,09 & 4,84 \\
\hline & Jul. & 0,17 & 3,28 & 4,69 & 0,01 & 3,10 & 4,60 \\
\hline & Ago. & 0,17 & 3,45 & 4,37 & 0,04 & 3,14 & 4,49 \\
\hline & Set. & 0,53 & 4,00 & 4,75 & 0,45 & 3,60 & 4,70 \\
\hline & Out. & 1,04 & 5,08 & 5,58 & 0,75 & 4,38 & 5,20 \\
\hline & Nov. & 0,72 & 5,84 & 6,03 & 0,83 & 5,25 & 5,63 \\
\hline & Dez. & 0,54 & 6,41 & 6,41 & 0,63 & 5,91 & 5,91 \\
\hline \multirow{12}{*}{2011} & Jan. & 1,15 & 1,15 & 6,21 & 0,83 & 0,83 & 5,99 \\
\hline & Fev. & 0,60 & 1,76 & 6,07 & 0,80 & 1,64 & 6,01 \\
\hline & Mar. & 0,35 & 2,11 & 6,08 & 0,79 & 2,44 & 6,30 \\
\hline & Abr. & 0,70 & 2,83 & 6,40 & 0,77 & 3,23 & 6,51 \\
\hline & Mai. & 0,31 & 3,15 & 6,50 & 0,47 & 3,71 & 6,55 \\
\hline & Jun. & 0,01 & 3,16 & 6,47 & 0,15 & 3,87 & 6,71 \\
\hline & Jul. & 0,30 & 3,47 & 6,61 & 0,16 & 4,04 & 6,87 \\
\hline & Ago. & 0,39 & 3,87 & 6,84 & 0,37 & 4,42 & 7,23 \\
\hline & Set. & 0,25 & 4,13 & 6,54 & 0,53 & 4,97 & 7,31 \\
\hline & Out. & 0,39 & 4,53 & 5,86 & 0,43 & 5,43 & 6,97 \\
\hline & Nov. & 0,60 & 5,16 & 5,73 & 0,52 & 5,97 & 6,64 \\
\hline & Dez. & 0,61 & 5,80 & 5,80 & 0,50 & 6,50 & 6,50 \\
\hline \multirow{5}{*}{2012} & Jan. & 0,66 & 0,66 & 5,29 & 0,56 & 0,56 & 6,22 \\
\hline & Fev. & $-0,07$ & 0,59 & 4,59 & 0,45 & 1,01 & 5,85 \\
\hline & Mar. & 0,15 & 0,74 & 4,38 & 0,21 & 1,22 & 5,24 \\
\hline & Abr. & 0,47 & 1,21 & 4,14 & 0,64 & 1,87 & 5,10 \\
\hline & Mai. & 0,35 & 1,57 & 4,18 & 0,36 & 2,24 & 4,99 \\
\hline
\end{tabular}

FONTE: IPEA, FIPE, IBGE. 
Índices de Preços

\begin{tabular}{|c|c|c|c|c|c|c|c|}
\hline \multirow{2}{*}{\multicolumn{2}{|c|}{ Período }} & \multicolumn{3}{|c|}{ IGP-M } & \multicolumn{3}{|c|}{ IGP-DI } \\
\hline & & Mensal & No ano & $\begin{array}{l}\text { Em } 12 \\
\text { meses }\end{array}$ & Mensal & No ano & $\begin{array}{l}\text { Em } 12 \\
\text { meses }\end{array}$ \\
\hline \multirow{12}{*}{2010} & Jan. & 0,63 & 0,63 & $-0,66$ & 1,01 & 1,01 & $-0,45$ \\
\hline & Fev. & 1,18 & 1,82 & 0,26 & 1,09 & 2,11 & 0,77 \\
\hline & Mar. & 0,94 & 2,77 & 1,95 & 0,63 & 2,75 & 2,26 \\
\hline & Abr. & 0,77 & 3,57 & 2,89 & 0,72 & 3,49 & 2,95 \\
\hline & Mai. & 1,19 & 4,80 & 4,19 & 1,57 & 5,12 & 4,38 \\
\hline & Jun. & 0,85 & 5,69 & 5,18 & 0,34 & 5,48 & 5,07 \\
\hline & Jul. & 0,15 & 5,85 & 5,79 & 0,22 & 5,71 & 5,98 \\
\hline & Ago. & 0,77 & 6,66 & 6,99 & 1,10 & 6,87 & 7,05 \\
\hline & Set. & 1,15 & 7,89 & 7,77 & 1,10 & 8,05 & 7,96 \\
\hline & Out. & 1,01 & 8,98 & 8,80 & 1,03 & 9,16 & 9,12 \\
\hline & Nov. & 1,45 & 10,56 & 10,27 & 1,58 & 10,88 & 10,76 \\
\hline & Dez. & 0,69 & 11,32 & 11,32 & 0,38 & 11,31 & 11,31 \\
\hline \multirow{12}{*}{2011} & Jan. & 0,79 & 0,79 & 11,50 & 0,98 & 0,98 & 11,27 \\
\hline & Fev. & 1,00 & 1,80 & 11,30 & 0,96 & 1,95 & 11,13 \\
\hline & Mar. & 0,62 & 2,43 & 10,95 & 0,61 & 2,57 & 11,11 \\
\hline & Abr. & 0,45 & 2,89 & 10,60 & 0,50 & 3,08 & 10,86 \\
\hline & Mai. & 0,43 & 3,33 & 9,76 & 0,01 & 3,09 & 9,16 \\
\hline & Jun. & $-0,18$ & 3,15 & 8,64 & $-0,13$ & 2,96 & 8,65 \\
\hline & Jul. & $-0,12$ & 3,02 & 8,35 & $-0,05$ & 2,91 & 8,36 \\
\hline & Ago. & 0,44 & 3,48 & 8,00 & 0,61 & 3,54 & 7,83 \\
\hline & Set. & 0,65 & 4,15 & 7,46 & 0,75 & 4,31 & 7,46 \\
\hline & Out. & 0,53 & 4,70 & 6,95 & 0,40 & 4,73 & 6,79 \\
\hline & Nov. & 0,50 & 5,22 & 5,95 & 0,43 & 5,18 & 5,58 \\
\hline & Dez. & $-0,12$ & 5,10 & 5,10 & $-0,16$ & 5,01 & 5,01 \\
\hline \multirow{5}{*}{2012} & Jan. & 0,25 & 0,25 & 4,53 & 0,30 & 0,30 & 4,31 \\
\hline & Fev. & $-0,06$ & 0,19 & 3,44 & 0,07 & 0,37 & 3,39 \\
\hline & Mar. & 0,43 & 0,62 & 3,24 & 0,56 & 0,93 & 3,33 \\
\hline & Abr. & 0,85 & 1,48 & 3,65 & 1,02 & 1,96 & 3,87 \\
\hline & Mai. & 1,02 & 2,51 & 4,26 & 0,91 & 2,89 & 4,80 \\
\hline
\end{tabular}

FONTE: FGV. 
Índices de Confiança

Índice de Confiança do Consumidor (ICC)

\begin{tabular}{llllll}
\hline \multicolumn{1}{c}{ Período } & $\mathbf{2 0 0 8}$ & $\mathbf{2 0 0 9}$ & $\mathbf{2 0 1 0}$ & $\mathbf{2 0 1 1}$ & $\mathbf{2 0 1 2}$ \\
\hline $1^{\text {o }}$ Trimestre & 145,74 & 130,05 & 160,61 & 161,78 & 164,29 \\
$2^{\text {o Trimestre }}$ & 146,17 & 131,76 & 156,99 & 155,42 & \\
$3^{\circ}$ Trimestre & 136,52 & 146,48 & 161,43 & 153,25 & \\
$4^{\circ}$ Trimestre & 134,32 & 156,52 & 159,90 & 155,17 & \\
\hline FONTE: IPEADATA. & & & & &
\end{tabular}

Índice de Confiança do Empresário Industrial - Geral (ICEI)

\begin{tabular}{lrrrrr}
\hline Período & 2008 & $\mathbf{2 0 0 9}$ & $\mathbf{2 0 1 0}$ & $\mathbf{2 0 1 1}$ & $\mathbf{2 0 1 2}$ \\
\hline $1^{\circ}$ Trimestre & 61,8 & 47,4 & 68,1 & 61,4 & 58,0 \\
$2^{\circ}$ Trimestre & 62,0 & 49,4 & 66,4 & 58,4 & \\
$3^{\circ}$ Trimestre & 58,1 & 58,2 & 63,6 & 56,9 & \\
$4^{\circ}$ Trimestre & 52,5 & 65,9 & 62,1 & 54,9 & \\
\hline
\end{tabular}

FONTE: CNI. 


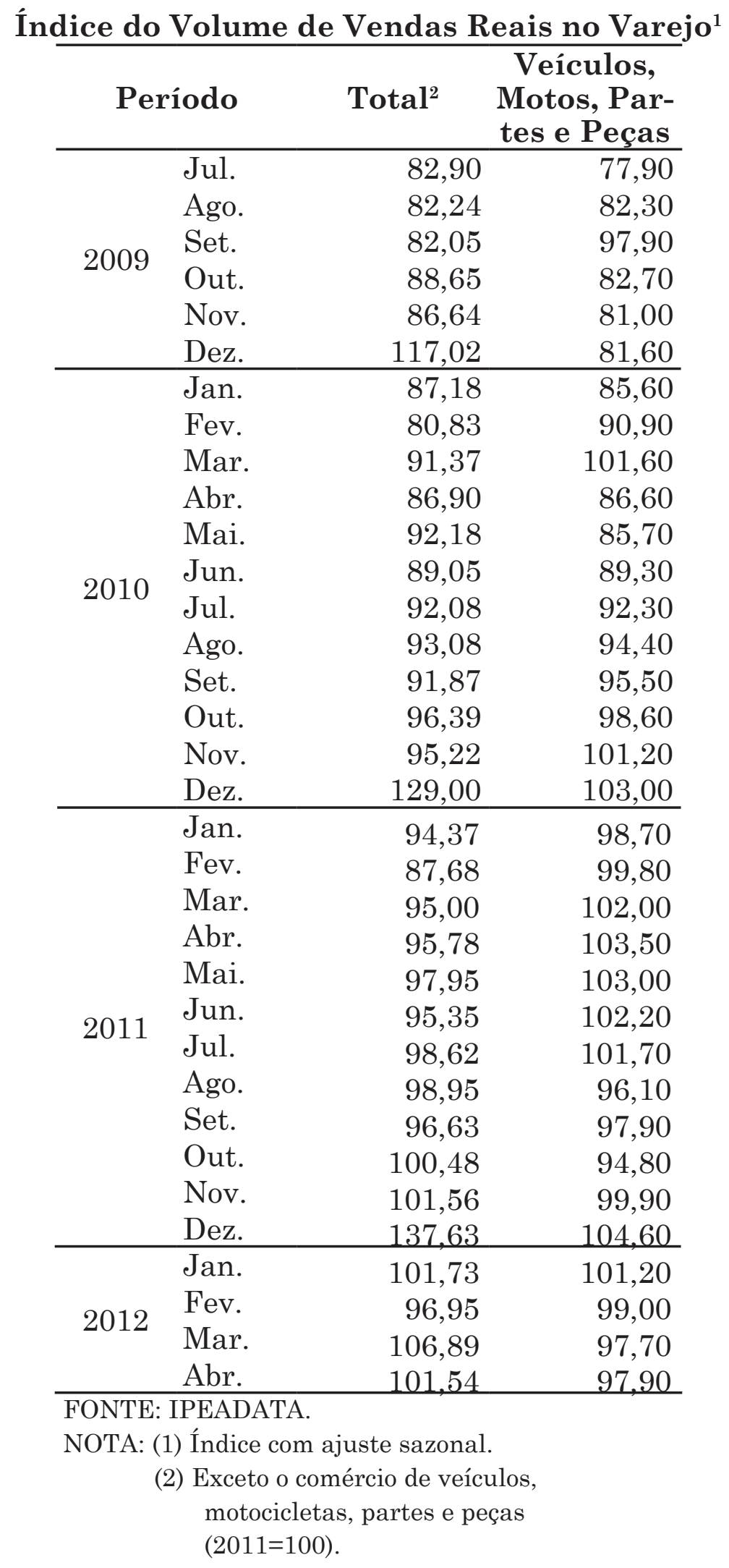




\section{Contas Nacionais}

Contas Nacionais

$\mathrm{R} \$$ (milhões) do segundo trimestre de 2012

\begin{tabular}{lrrrrrr}
\hline Período & PIB & $\begin{array}{c}\text { Consu- } \\
\text { mo das } \\
\text { famílias }\end{array}$ & $\begin{array}{c}\text { Consu- } \\
\text { mo do } \\
\text { governo }\end{array}$ & FBKF & Export. & Import. \\
\hline 2003 & 3.041 .228 & 1.755 .948 & 641.783 & 434.842 & 330.745 & 201.379 \\
2004 & 3.215 .001 & 1.823 .035 & 668.041 & 474.495 & 381.326 & 228.172 \\
2005 & 3.316 .478 & 1.904 .470 & 683.448 & 491.697 & 416.906 & 247.497 \\
2006 & 3.447 .658 & 2.003 .419 & 701.034 & 539.748 & 437.925 & 293.158 \\
2007 & 3.657 .809 & 2.125 .083 & 736.985 & 614.506 & 465.070 & 351.421 \\
2008 & 3.846 .892 & 2.245 .573 & 760.343 & 697.910 & 467.607 & 405.387 \\
2009 & 3.834 .265 & 2.345 .305 & 783.970 & 650.987 & 424.934 & 374.585 \\
2010 & 4.123 .124 & 2.508 .174 & 817.190 & 789.870 & 473.881 & 508.823 \\
$2011 . I$ & 1.025 .628 & 642.564 & 196.487 & 197.261 & 107.862 & 124.887 \\
$2011 . I I$ & 1.068 .679 & 647.803 & 207.367 & 204.135 & 125.364 & 138.695 \\
$2011 . I I I$ & 1.073 .717 & 655.270 & 204.283 & 216.461 & 134.082 & 147.433 \\
$2011 . I V$ & 1.067 .763 & 665.239 & 224.798 & 209.248 & 127.846 & 147.413 \\
2011 & 4.235 .788 & 2.610 .876 & 832.937 & 827.107 & 495.155 & 558.429 \\
$2012 . I$ & 1.033 .349 & 658.906 & 203.095 & 193.198 & 115.029 & 132.776 \\
\hline
\end{tabular}

FONTE: Sistema de Contas Nacionais (IBGE).

Contas Nacionais

Variação Percentual por Período

\begin{tabular}{lrrrrrr}
\hline Período & PIB & $\begin{array}{c}\text { Consu- } \\
\text { mo das } \\
\text { famílias }\end{array}$ & $\begin{array}{c}\text { Consu- } \\
\text { mo do } \\
\text { governo }\end{array}$ & FBKF & Export. & Import. \\
\hline 2001 & 1,31 & 0,68 & 2,75 & 0,44 & 10,05 & 1,52 \\
2002 & 2,66 & 1,93 & 4,74 & $-5,23$ & 7,42 & $-11,82$ \\
2003 & 1,15 & $-0,78$ & 1,15 & $-4,59$ & 10,40 & $-1,62$ \\
2004 & 5,71 & 3,82 & 4,09 & 9,12 & 15,29 & 13,30 \\
2005 & 3,16 & 4,47 & 2,31 & 3,63 & 9,33 & 8,47 \\
2006 & 3,96 & 5,20 & 2,57 & 9,77 & 5,04 & 18,45 \\
2007 & 6,10 & 6,07 & 5,13 & 13,85 & 6,20 & 19,87 \\
2008 & 5,17 & 5,67 & 3,17 & 13,57 & 0,55 & 15,36 \\
2009 & $-0,33$ & 4,44 & 3,11 & $-6,72$ & $-9,13$ & $-7,60$ \\
2010 & 7,53 & 6,94 & 4,24 & 21,33 & 11,52 & 35,84 \\
2011 & 2,73 & 4,09 & 1,93 & 4,71 & 4,49 & 9,75 \\
$2012 . I^{*}$ & 0,75 & 2,54 & 3,36 & $-2,06$ & 6,64 & 6,32 \\
\hline
\end{tabular}

FONTE: Sistema de Contas Nacionais (IBGE).

NOTA: (*) Variação percentual sobre o mesmo período do ano anterior. 
Finanças Públicas

\begin{tabular}{lccccc}
\hline \multicolumn{1}{c}{ Descrição } & $\mathbf{2 0 0 8}$ & $\mathbf{2 0 0 9}$ & $\mathbf{2 0 1 0}$ & $\mathbf{2 0 1 1}$ & $\mathbf{2 0 1 2}^{\text {(a) }}$ \\
\hline DLSP $^{1}-$ Total & 34,31 & 42,80 & 39,10 & 36,40 & 35,70 \\
DLSP $^{2}-$ Externa & $-11,10$ & $-9,18$ & $-9,50$ & $-13,00$ & $-13,80$ \\
DLSP $^{3}-$ Interna & 49,89 & 50,20 & 48,70 & 49,40 & 49,50 \\
Necessidade Financ. do Set. Público $^{4}$ & 5,51 & 5,44 & 5,32 & 5,71 & 5,49 \\
Superávit Primário $^{5}$ & $-3,45$ & $-2,06$ & $-2,77$ & $-3,11$ & $-4,34$ \\
Déficit Nominal $^{6}$ & 2,26 & 3,38 & 2,55 & 2,61 & 1,15 \\
\hline
\end{tabular}

FONTE: Banco Central.

NOTA: (a) Dados contabilizados até Abril de 2012.

(1) Dívida Líquida do Setor Público (\% PIB) - Tot. - Set. públ. consolidado - \% - M.

(2) Dívida Líquida do Setor Público (\% PIB) - Ext. - Set. públ. consolidado - \% - M.

(3) Dívida Líquida do Setor Público (\% PIB) - Int. - Set. públ. consolidado - \% - M.

(4) NFSP c/ desv. cambial (\% PIB) - Acumulado em 12 meses - Juros nominais Set. público consolidado - \%.

(5) NFSP c/ desv. cambial (\% PIB) - Acumulado em 12 meses - Resultado primário Set. público consolidado - \%.

(6) NFSP s/ desv. cambial (\% PIB) - Acumulado em 12 meses - Resultado nominal Set. público consolidado - \%.

Receitas e Despesas*

\begin{tabular}{cccccc}
\hline Descrição & $\mathbf{2 0 0 8}$ & $\mathbf{2 0 0 9}$ & $\mathbf{2 0 1 0}$ & $\mathbf{2 0 1 1}$ & $\mathbf{2 0 1 2}^{\text {(a) }}$ \\
\hline Receita Total & 716.647 & 739.304 & 919.773 & 990.406 & 441.721 \\
Receitas do Tesouro & 551.332 & 555.054 & 705.297 & 741.296 & 336.385 \\
Receita Bruta & 564.720 & 569.846 & 719.531 & 757.428 & 339.702 \\
(-) Restituições & -13.388 & -14.737 & -14.135 & -15.858 & -3.179 \\
(-) Incentivos Fiscais & -1 & -55 & -99 & -274 & -137 \\
Receitas da Previdência & 163.355 & 182.009 & 211.968 & 245.892 & 104.208 \\
Receitas do BCB $_{\text {Transferências }}^{1}$ & 1.745 & 2.242 & 2.508 & 3.217 & 1.127 \\
Receita Líquida Total $^{2}$ & 133.074 & 127.684 & 140.678 & 172.483 & 81.718 \\
Despesa Total $_{\text {Pessoal e Encargos Sociais }}$ & 437.200 & 611.621 & 779.095 & 817.922 & 361.003 \\
Benefícios Previdenciários & 121.370 & 151.653 & 166.486 & 179.276 & 74.759 \\
Custeio e Capital & 182.907 & 224.876 & 258.859 & 281.438 & 122.010 \\
Transf. do Tesouro ao BCB & 164.336 & 191.825 & 274.544 & 258.160 & 115.176 \\
Despesas do BCB & $2.042,5$ & 1.180 & 1.242 & 2.135 & 910 \\
\hline FONTE: Tesouro Nacional. & & 2.872 & 3.027 & 3.769 & 1.337 \\
\hline
\end{tabular}

FONTE: Tesouro Nacional.

NOTA: (*) em milhões de R $\$$.

(a) Dados contabilizados até Maio de 2012.

(1) Transferências concedidas aos Estados e Municípios.

(2) Receita Total menos Transferências. 
Atividade Industrial

\begin{tabular}{|c|c|c|c|c|c|c|}
\hline Período & $\begin{array}{c}\text { Bens de } \\
\text { capital }\end{array}$ & $\begin{array}{c}\text { Bens } \\
\text { intermedi- } \\
\text { ários }\end{array}$ & $\begin{array}{c}\text { Bens de } \\
\text { cons. durá- } \\
\text { veis }\end{array}$ & $\begin{array}{c}\text { Bens de } \\
\text { cons. não- } \\
\text { duráveis }\end{array}$ & $\begin{array}{l}\text { Indústria } \\
\text { de trans- } \\
\text { formação }\end{array}$ & $\begin{array}{c}\text { Capacida- } \\
\text { de instala- } \\
\text { da (\%) }\end{array}$ \\
\hline Jan. & 158.44 & 104.20 & 118.13 & 108.22 & 97.07 & 76.70 \\
\hline Fev. & 143,90 & 101,05 & 119,43 & 107,03 & 94,34 & 77,00 \\
\hline Mar. & 141,35 & 102,70 & 136,00 & 107,82 & 110,30 & 77,10 \\
\hline Abr. & 136,89 & 104,09 & 142,82 & 108,96 & 105,71 & 77,60 \\
\hline Maio & 136,15 & 105,11 & 146,75 & 110,07 & 113,46 & 78,70 \\
\hline Jun. & 139,57 & 106,53 & 151,54 & 110,14 & 114,49 & 79,00 \\
\hline 2009 Jul. & 143,05 & 108,14 & 157,20 & 110,31 & 122,05 & 79,80 \\
\hline Ago. & 146,08 & 109,98 & 162,67 & 110,36 & 124,84 & 81,60 \\
\hline Set. & 150,74 & 112,00 & 166,36 & 110,90 & 125,40 & 82,80 \\
\hline Out. & 156.77 & 113.89 & 171.34 & 111.71 & 133.79 & 83.70 \\
\hline Nov. & 164,75 & 115,80 & 172,07 & 112,10 & 128,39 & 84,50 \\
\hline Dez. & 170.34 & 117.39 & 169.93 & 113.41 & 117.25 & 84.20 \\
\hline Jan. & 173,46 & 119,28 & 168,64 & 114,31 & 112,38 & 82,10 \\
\hline Fev. & 174,64 & 120,11 & 169,63 & 115,81 & 111,34 & 83,10 \\
\hline Mar. & 176,88 & 121,18 & 173,40 & 117,11 & 132,87 & 83,50 \\
\hline Abr. & 181,05 & 121,76 & 173,62 & 117,74 & 123,99 & 84,50 \\
\hline Maio & 184,63 & 122,61 & 173.93 & 117,42 & 130,20 & 84.60 \\
\hline Jun. & 185,26 & 122,66 & 172,39 & 116,59 & 127,27 & 85,10 \\
\hline 2010 Jul. & 183.79 & 122,80 & 170,79 & 116,08 & 132,61 & 85.00 \\
\hline Ago. & 183,05 & 122,50 & 169,41 & 115,76 & 135,48 & 85,40 \\
\hline Set. & 182,84 & 122,33 & 170,27 & 116,36 & 133,32 & 85.90 \\
\hline Out. & 182,40 & 121,85 & 172,25 & 116,71 & 135,88 & 86,40 \\
\hline Nov. & 183,95 & 122,21 & 174,33 & 118,06 & 134,92 & 86,10 \\
\hline Dez. & 184.55 & 122,45 & 175,54 & 116,36 & 119.66 & 85.30 \\
\hline Jan. & 186,43 & 122,52 & 177,18 & 116,32 & 115,08 & 83,10 \\
\hline Fev. & 187,24 & 122,82 & 178,62 & 116,36 & 119,88 & 83,70 \\
\hline Mar. & 191,97 & 123,17 & 182,95 & 117,57 & 131,42 & 83,50 \\
\hline Abr. & 192,36 & 123,31 & 178,94 & 117,69 & 121,65 & 84.00 \\
\hline Mai. & 192,45 & 123,58 & 176,22 & 118,01 & 133,37 & 84,10 \\
\hline 2011 Jun. & 189,40 & 123,28 & 170,59 & 116,26 & 128,25 & 84,10 \\
\hline 2011 Jul. & 190,98 & 123,13 & 172,99 & 116,48 & 131,78 & 84,00 \\
\hline Ago. & 192,64 & 122,29 & 172,02 & 116,17 & 138,30 & 84.00 \\
\hline Set. & 190,87 & 122,04 & 166,41 & 116,57 & 131,10 & 84,40 \\
\hline Out. & 186,37 & 121,73 & 160,24 & 115,11 & 132,62 & 84,70 \\
\hline Nov. & 181,95 & 121,59 & 155,90 & 114,94 & 130,83 & 84,50 \\
\hline Dez. & 183.77 & 121.58 & 159.99 & 115.39 & 117.85 & 84.10 \\
\hline Jan. & 176,83 & 120,83 & 161,48 & 116,77 & 112,11 & 82,10 \\
\hline 2012 Fev. & 171,86 & 120,78 & 160,58 & 117,59 & 114,66 & 82,90 \\
\hline 2012 Mar. & 166,51 & 120,30 & 157,90 & 117,85 & 128,69 & 83,00 \\
\hline Abr. & 172.28 & 120,71 & 156,87 & 117,31 & 117,93 & 83,50 \\
\hline
\end{tabular}

FONTE: IBGE, IPEADATA.

NOTA: Séries com ajustes sazonais (2002=100) Média Móvel Trimestral Janeiro/2010 - Fevereiro/2012, exceto Capacidade instalada. 


\section{Consumo de Energia}

Carga de energia SIN - GWh

\begin{tabular}{ccccccc}
\hline Período & $\mathbf{2 0 0 7}$ & $\mathbf{2 0 0 8}$ & $\mathbf{2 0 0 9}$ & $\mathbf{2 0 1 0}$ & $\mathbf{2 0 1 1}$ & $\mathbf{2 0 1 2}$ \\
\hline Jan. & 36590,42 & 37860,46 & 36307,74 & 40300,76 & 41973,24 & 43144,05 \\
Fev. & 33585,69 & 35930,94 & 34406,66 & 38379,57 & 39748,31 & 42828,12 \\
Mar. & 38691,68 & 38632,24 & 39112,50 & 42290,46 & 42272,70 & 46146,46 \\
Abr. & 36099,71 & 37352,08 & 35734,16 & 38530,86 & 40334,90 & 42729,34 \\
Maio & 36004,88 & 37167,15 & 36201,22 & 39199,79 & 40359,61 & 42271,03 \\
Jun. & 34410,14 & 36260,19 & 34605,66 & 37565,50 & 38493,09 & 40398,97 \\
Jul. & 35672,29 & 37567,80 & 36534,17 & 39173,21 & 40103,95 & \\
Ago. & 36594,24 & 38409,13 & 36909,55 & 39487,01 & 41871,28 & \\
Set. & 35897,48 & 37246,67 & 37025,88 & 39289,79 & 40575,20 & \\
Out. & 38095,16 & 39278,23 & 38431,41 & 40134,27 & 41843,00 & \\
Nov. & 36424,40 & 36594,86 & 38871,71 & 39401,42 & 40884,92 & \\
Dez. & 37618,65 & 35773,12 & 39218,90 & 41351,04 & 42811,70 & \\
\hline
\end{tabular}

FONTE: Operador Nacional do Sistema Elétrico.

Taxa de Desemprego

\begin{tabular}{crrrrrrrrrr}
\hline \multirow{2}{*}{ Período o } & \multicolumn{1}{c}{$\mathbf{2 0 0 8}$} & \multicolumn{1}{c}{$\mathbf{2 0 0 9}$} & \multicolumn{2}{c}{$\mathbf{2 0 1 0}$} & \multicolumn{2}{c}{$\mathbf{2 0 1 1}$} & \multicolumn{2}{c}{$\mathbf{2 0 1 2}$} \\
\cline { 2 - 10 } & Média $^{1}$ & RMC $^{2}$ & Média $^{1}$ & RMC $^{2}$ & Média $^{1}$ & RMC $^{2}$ & Média $^{1}$ & RMC $^{2}$ & Média $^{1}$ & RMC $^{2}$ \\
\hline Jan. & 8,0 & 4,8 & 8,2 & 5,4 & 7,2 & 5,4 & 6,1 & 3,5 & 5,5 & 3,8 \\
Fev. & 8,7 & 5,9 & 8,5 & 6,3 & 7,4 & 5,6 & 6,4 & 4,0 & 5,7 & 3,7 \\
Mar. & 8,6 & 5,8 & 9,0 & 6,3 & 7,6 & 5,5 & 6,5 & 3,8 & 6,2 & 4,5 \\
Abr. & 8,5 & 6,3 & 8,9 & 6,1 & 7,3 & 5,0 & 6,4 & 3,7 & 6,0 & 4,3 \\
Maio & 7,9 & 6,2 & 8,8 & 5,5 & 7,5 & 5,2 & 6,4 & 4,4 & 5,8 & 4,69 \\
Jun. & 7,8 & 6,2 & 8,1 & 5,2 & 7,0 & 4,8 & 6,2 & 4,1 & & \\
Jul. & 8,1 & 5,8 & 8,0 & 5,6 & 6,9 & 4,3 & 6,0 & 3,7 & & \\
Ago. & 7,6 & 5,4 & 8,1 & 5,7 & 6,7 & 4,5 & 6,0 & 3,8 & & \\
Set. & 7,6 & 4,5 & 7,7 & 5,0 & 6,2 & 3,5 & 6,0 & 3,4 & & \\
Out. & 7,5 & 4,6 & 7,5 & 4,9 & 6,1 & 3,4 & 5,8 & 3,6 & & \\
Nov. & 7,6 & 4,8 & 7,4 & 4,5 & 5,7 & 3,4 & 5,2 & 3,4 & & \\
Dez. & 6,8 & 4,2 & 6,8 & 3,8 & 5,3 & 2,8 & 4,7 & 3,0 & & \\
\hline FOnyyyyyyyyyyy
\end{tabular}

FONTE: IBGE/PME; Instituto Paranaense de Desenvolvimento Econômico e Social (Ipardes). NOTA: (1) Média do índice em Recife, Salvador, Belo Horizonte, Rio de Janeiro, São Paulo e Porto Alegre.

(2) RMC - Região Metropolitana de Curitiba. 


\section{Pessoal Ocupado e Rendimentos}

\begin{tabular}{|c|c|c|c|c|}
\hline \multicolumn{2}{|c|}{ Período } & $\begin{array}{l}\text { População } \\
\text { Ocupada } \\
\text { (mil) }\end{array}$ & $\begin{array}{l}\text { Rendimento } \\
\text { Médio Real } \\
(\mathrm{R} \$) \\
\end{array}$ & $\begin{array}{l}\text { Massa de Rendi- } \\
\text { mento Real Efeti- } \\
\text { vo (milhões) }\end{array}$ \\
\hline \multirow{12}{*}{2009} & Jan. & 21.200 & $1.577,53$ & 33.595 \\
\hline & Fev. & 20.900 & $1.575,29$ & 33.210 \\
\hline & Mar. & 21.000 & $1.572,37$ & 33.218 \\
\hline & Abr. & 20.913 & $1.560,96$ & 32.980 \\
\hline & Maio. & 21.000 & $1.544,12$ & 32.756 \\
\hline & Jun. & 21.148 & $1.538,94$ & 32.929 \\
\hline & Jul. & 21.332 & $1.547,06$ & 33.261 \\
\hline & Ago. & 21.444 & $1.561,72$ & 33.823 \\
\hline & Set. & 21.520 & $1.570,88$ & 34.132 \\
\hline & Out. & 21.505 & $1.570,64$ & 34.213 \\
\hline & Nov. & 21.603 & $1.569,31$ & 34.350 \\
\hline & Dez. & 21.815 & $1.555,20$ & 34.273 \\
\hline \multirow{12}{*}{2010} & Jan. & 21.605 & $1.571,59$ & 34.307 \\
\hline & Fev. & 21.668 & $1.589,74$ & 34.752 \\
\hline & Mar. & 21.748 & $1.595,41$ & 34.946 \\
\hline & Abr. & 21.820 & $1.596,28$ & 34.143 \\
\hline & Maio. & 21.878 & $1.582,07$ & 34.938 \\
\hline & Jun. & 21.878 & $1.590,59$ & 35.125 \\
\hline & Jul. & 22.020 & $1.625,26$ & 36.168 \\
\hline & Ago. & 22.135 & $1.647,86$ & 36.810 \\
\hline & Set. & 22.282 & $1.668,81$ & 37.586 \\
\hline & Out. & 22.345 & $1.673,12$ & 37.898 \\
\hline & Nov. & 22.400 & $1.659,50$ & 37.653 \\
\hline & Dez. & 22.450 & $1.647,25$ & 37.483 \\
\hline \multirow{12}{*}{2011} & Jan. & 22.080 & $1.655,56$ & 37.196 \\
\hline & Fev. & 22.184 & $1.647,90$ & 36.992 \\
\hline & Mar. & 22.279 & $1.656,49$ & 37.292 \\
\hline & Abr. & 22.313 & $1.626,48$ & 36.648 \\
\hline & Mai. & 22.430 & $1.645,36$ & 37.250 \\
\hline & Jun. & 22.390 & $1.654,22$ & 37.316 \\
\hline & Jul. & 22.476 & $1.690,93$ & 38.333 \\
\hline & Ago. & 22.623 & $1.699,88$ & 38.859 \\
\hline & Set. & 22.651 & $1.669,08$ & 38.110 \\
\hline & Out. & 22.682 & $1.668,79$ & 38.230 \\
\hline & Nov. & 22.830 & $1.670,99$ & 38.478 \\
\hline & Dez. & 22.734 & $1.689,75$ & 38.739 \\
\hline \multirow{5}{*}{2012} & Jan. & 22.513 & $1.700,97$ & 38.528 \\
\hline & Fev. & 22.611 & $1.720,99$ & 39.143 \\
\hline & Mar. & 22.646 & $1.748,58$ & 39.908 \\
\hline & Abr. & 22.709 & $1.727,88$ & 39.564 \\
\hline & Mai. & 22.984 & $1.725,60$ & 40.032 \\
\hline
\end{tabular}

FONTE: IBGE. 
Taxa de Juros e Reservas Internacionais

\begin{tabular}{|c|c|c|c|}
\hline \multicolumn{4}{|c|}{ Taxa de Juros } \\
\hline \multicolumn{2}{|c|}{ Período } & Meta Selic & $\begin{array}{c}\text { Selic efe- } \\
\text { tiva }\end{array}$ \\
\hline \multirow{6}{*}{2009} & Jul. & 9,25 & 9,16 \\
\hline & Ago. & 8,75 & 8,65 \\
\hline & Set. & 8,75 & 8,65 \\
\hline & Out. & 8,75 & 8,65 \\
\hline & Nov. & 8,75 & 8,65 \\
\hline & Dez. & 8,75 & 8,65 \\
\hline \multirow{12}{*}{2010} & Jan. & 8,75 & 8,65 \\
\hline & Fev. & 8,75 & 8,65 \\
\hline & Mar. & 8,75 & 8,65 \\
\hline & Abr. & 8,75 & 8,65 \\
\hline & Mai. & 9,50 & 9,40 \\
\hline & Jun. & 10,25 & 10,16 \\
\hline & Jul. & 10,25 & 10,16 \\
\hline & Ago. & 10,75 & 10,66 \\
\hline & Set. & 10,75 & 10,66 \\
\hline & Out. & 10,75 & 10,66 \\
\hline & Nov. & 10,75 & 10,66 \\
\hline & Dez. & 10,75 & 10,66 \\
\hline \multirow{12}{*}{2011} & Jan. & 10,75 & 10,66 \\
\hline & Fev. & 10,75 & 10,66 \\
\hline & Mar. & 11,25 & 11,17 \\
\hline & Abr. & 11,75 & 11,67 \\
\hline & Mai. & 11,75 & 11,67 \\
\hline & Jun. & 12,00 & 11,92 \\
\hline & Jul. & 12,25 & 12,17 \\
\hline & Ago. & 12,50 & 12,42 \\
\hline & Set. & 12,50 & 12,42 \\
\hline & Out. & 12,00 & 11,90 \\
\hline & Nov. & 11,50 & 11,40 \\
\hline & Dez. & 11,00 & 10,90 \\
\hline \multirow{5}{*}{2012} & Jan. & 10,50 & 10,40 \\
\hline & Fev. & 10,50 & 9,65 \\
\hline & Mar. & 9,75 & 8,90 \\
\hline & Abr. & 9,00 & \\
\hline & Mai. & 8,50 & \\
\hline
\end{tabular}

FONTE: Banco Central do Brasil.

\begin{tabular}{|c|c|c|c|}
\hline \multicolumn{4}{|c|}{ Reservas Internacionais } \\
\hline \multicolumn{2}{|c|}{ Período } & $\begin{array}{l}\text { US\$ mi- } \\
\text { lhões }\end{array}$ & $\begin{array}{c}\text { Variação } \\
(\%)\end{array}$ \\
\hline \multirow{6}{*}{2009} & Jul. & 207.363 & 2,93 \\
\hline & Ago. & 215.744 & 4,04 \\
\hline & Set. & 221.629 & 2,73 \\
\hline & Out. & 231.123 & 4,28 \\
\hline & Nov. & 236.660 & 2,40 \\
\hline & Dez. & 238.520 & 0,79 \\
\hline \multirow{12}{*}{2010} & Jan. & 240.484 & 0,82 \\
\hline & Fev. & 241.033 & 0,23 \\
\hline & Mar. & 243.762 & 1,13 \\
\hline & Abr. & 247.292 & 1,45 \\
\hline & Mai. & 249.846 & 1,03 \\
\hline & Jun. & 253.114 & 1,31 \\
\hline & Jul. & 257.299 & 1,65 \\
\hline & Ago. & 261.320 & 1,56 \\
\hline & Set. & 275.206 & 5,31 \\
\hline & Out. & 284.930 & 3,53 \\
\hline & Nov. & 285.461 & 0,19 \\
\hline & Dez. & 288.575 & 1,09 \\
\hline \multirow{12}{*}{2011} & Jan. & 297.696 & 3,16 \\
\hline & Fev. & 307.516 & 3,30 \\
\hline & Mar. & 317.146 & 3,13 \\
\hline & Abr. & 328.062 & 3,44 \\
\hline & Mai. & 333.017 & 1,51 \\
\hline & Jun. & 335.775 & 0,83 \\
\hline & Jul. & 346.144 & 3,09 \\
\hline & Ago. & 353.397 & 2,10 \\
\hline & Set. & 349.708 & $-1,04$ \\
\hline & Out. & 352.928 & 0,92 \\
\hline & Nov. & 352.073 & $-0,24$ \\
\hline & Dez. & 352.012 & $-0,02$ \\
\hline \multirow{6}{*}{2012} & Jan. & 355.075 & 0,87 \\
\hline & Fev. & 356.330 & 0,35 \\
\hline & Mar. & 365.216 & 2,49 \\
\hline & Abr. & 374.272 & 2,48 \\
\hline & Mai. & 372.409 & $-0,50$ \\
\hline & Jun. & 372.957 & 0,15 \\
\hline
\end{tabular}

FONTE: Banco Central do Brasil. 
Setor Externo

\begin{tabular}{|c|c|c|c|c|c|c|}
\hline \multirow{2}{*}{\multicolumn{2}{|c|}{ Período }} & \multicolumn{3}{|c|}{ Balança Comercial } & \multicolumn{2}{|c|}{ Transações Correntes } \\
\hline & & \multirow{2}{*}{$\begin{array}{l}\begin{array}{l}\text { Expor- } \\
\text { tações } \\
\text { (FOB) }^{1}\end{array} \\
14.142\end{array}$} & \multirow{2}{*}{$\begin{array}{l}\begin{array}{c}\text { Impor- } \\
\text { tações } \\
\text { (FOB) }^{1}\end{array} \\
11.231\end{array}$} & Saldo $^{1}$ & \multirow{2}{*}{$\begin{array}{r}\begin{array}{c}\text { Saldo Transa- } \\
\text { ções Correntes }\end{array} \\
-1.623\end{array}$} & \multirow{2}{*}{$\begin{array}{l}\begin{array}{c}\text { Percentual do } \\
\text { PIB em 12 } \\
\text { meses }\end{array} \\
-1,25\end{array}$} \\
\hline \multirow{7}{*}{2009} & Jul. & & & 2.911 & & \\
\hline & Ago. & 13.841 & 10.788 & 3.053 & -809 & $-1,23$ \\
\hline & Set. & 13.863 & 12.554 & 1.309 & -2.452 & $-1,19$ \\
\hline & Out. & 14.082 & 12.766 & 1.316 & -3.018 & $-1,29$ \\
\hline & Nov. & 12.653 & 12.042 & 610 & -3.273 & $-1,41$ \\
\hline & Dez. & 14.463 & 12.294 & 2.169 & -5.950 & $-1,55$ \\
\hline & Total & 152.996 & 127.723 & 25.273 & -24.302 & - \\
\hline \multirow{13}{*}{2010} & Jan. & 11.305 & 11.485 & -180 & -3.830 & $-1,52$ \\
\hline & Fev. & 12.197 & 11.808 & 389 & -3.082 & $-1,61$ \\
\hline & Mar. & 15.727 & 15.055 & 672 & -5.005 & $-1,73$ \\
\hline & Abr. & 15.161 & 13.878 & 1.283 & -4.618 & $-1,91$ \\
\hline & Maio & 17.703 & 14.248 & 3.455 & -2.007 & $-1,87$ \\
\hline & Jun. & 17.094 & 14.827 & 2.267 & -5.278 & $-2,05$ \\
\hline & Jul. & 17.673 & 16.329 & 1.344 & -4.589 & $-2,15$ \\
\hline & Ago. & 19.236 & 16.844 & 2.393 & -2.985 & $-2,23$ \\
\hline & Set. & 18.833 & 17.753 & 1.080 & -3.959 & $-2,29$ \\
\hline & Out. & 18.380 & 16.549 & 1.832 & -3.697 & $-2,32$ \\
\hline & Nov. & 17.687 & 17.396 & 292 & -4.728 & $-2,38$ \\
\hline & Dez. & 20.918 & 15.561 & 5.358 & -3.495 & $-2,20$ \\
\hline & Total & 201.915 & 181.694 & 20.221 & -47.273 & - \\
\hline \multirow{13}{*}{2011} & Jan. & 15.214 & 14.802 & 412 & -5.572 & $-2,26$ \\
\hline & Fev. & 16.732 & 15.537 & 1.196 & -3.469 & $-2,24$ \\
\hline & Mar. & 19.286 & 17.736 & 1.550 & -5.737 & $-2,25$ \\
\hline & Abr. & 20.173 & 18.311 & 1.862 & -3.598 & $-2,17$ \\
\hline & Mai. & 23.209 & 19.690 & 3.519 & -4.180 & $-2,24$ \\
\hline & Jun. & 23.689 & 19.262 & 4.428 & -3.477 & $-2,13$ \\
\hline & Jul. & 22.252 & 19.117 & 3.135 & -3.558 & $-2,07$ \\
\hline & Ago. & 26.159 & 22.285 & 3.874 & -4.849 & $-2,12$ \\
\hline & Set. & 23.285 & 20.212 & 3.073 & -2.234 & $-2,03$ \\
\hline & Out. & 22.140 & 19.785 & 2.355 & -3.157 & $-1,98$ \\
\hline & Nov. & 21.773 & 21.191 & 582 & -6.640 & $-2,04$ \\
\hline & Dez. & 22.127 & 18.316 & 3.811 & -6.008 & $-2,12$ \\
\hline & Total & 256.039 & 226.244 & 29.797 & -52.480 & \\
\hline \multirow{5}{*}{2012} & Jan. & 16.141 & 17.437 & -1.296 & -7.056 & $-2,19$ \\
\hline & Fev. & 18.028 & 16.314 & 1.714 & -1.728 & $-2,13$ \\
\hline & Mar. & 20.911 & 18.892 & 2.019 & -3.304 & $-2,04$ \\
\hline & Abr. & 19.566 & 18.685 & 882 & -5.403 & $-2,13$ \\
\hline & Mai. & 23.215 & 20.262 & 2.953 & -3.468 & $-2,11$ \\
\hline
\end{tabular}

FONTE: Banco Central do Brasil, SECEX/ MDIC.

NOTA: (1) em US\$ milhões. 
Taxa de Câmbio

\begin{tabular}{|c|c|c|c|}
\hline \multicolumn{2}{|c|}{ Período } & \multicolumn{2}{|c|}{$\begin{array}{c}\text { Taxa de câmbio real } \\
\text { efetiva }\end{array}$} \\
\hline & & IPA-OG & INPC \\
\hline \multirow{6}{*}{2009} & Jul. & 88,53 & 87,20 \\
\hline & Ago. & 88,25 & 83,93 \\
\hline & Set. & 84,25 & 83,10 \\
\hline & Out. & 81,26 & 79,86 \\
\hline & Nov. & 81,62 & 79,82 \\
\hline & Dez. & 83,04 & 80,83 \\
\hline \multirow{12}{*}{2010} & Jan. & 83,57 & 81,46 \\
\hline & Fev. & 84,44 & 82,87 \\
\hline & Mar. & 82,45 & 80,78 \\
\hline & Abr. & 81,37 & 79,67 \\
\hline & Maio & 81,37 & 80,98 \\
\hline & Jun. & 80,58 & 80,65 \\
\hline & Jul. & 80,52 & 80,92 \\
\hline & Ago. & 79,98 & 81,83 \\
\hline & Set. & 78,03 & 80,57 \\
\hline & Out. & 78,12 & 80,99 \\
\hline & Nov. & 78,65 & 82,29 \\
\hline & Dez. & 78,16 & 81,49 \\
\hline \multirow{12}{*}{2011} & Jan. & 77,26 & 80,55 \\
\hline & Fev. & 77,92 & 81,76 \\
\hline & Mar. & & 83,03 \\
\hline & Abr. & & 81,28 \\
\hline & Mai. & & 83,59 \\
\hline & Jun. & & 83,62 \\
\hline & Jul. & & 84,18 \\
\hline & Ago. & & 87,26 \\
\hline & Set & & 95,89 \\
\hline & Out. & & 98,00 \\
\hline & Nov. & & 99,79 \\
\hline & Dez. & & 90,53 \\
\hline \multirow{3}{*}{2012} & Jan. & & 84,56 \\
\hline & Fev. & & 84,01 \\
\hline & Mar. & & 85,43 \\
\hline
\end{tabular}

FONTE: IPEA.

NOTA: Índices ponderados, base ano $2005=100$. 
Agregados Monetários

\begin{tabular}{|c|c|c|c|c|c|}
\hline \multicolumn{2}{|c|}{ Período } & $\begin{array}{c}\text { Base } \\
\text { monetá- } \\
\text { ria* }\end{array}$ & $\mathbf{M}^{1}$ & $\mathrm{M}^{2}{ }^{2}$ & $\mathbf{M}^{3}$ \\
\hline \multirow{6}{*}{2009} & Jul. & 4,40 & 6,40 & 35,40 & 65,70 \\
\hline & Ago. & 4,40 & 6,50 & 35,40 & 66,50 \\
\hline & Set. & 4,60 & 6,70 & 35,80 & 67,50 \\
\hline & Out. & 4,70 & 6,70 & 35,50 & 67,80 \\
\hline & Nov. & 4,90 & 6,90 & 35,70 & 68,10 \\
\hline & Dez. & 5,10 & 7,70 & 36,00 & 68,10 \\
\hline \multirow{12}{*}{2010} & Jan. & 4,70 & 6,90 & 35,00 & 66,90 \\
\hline & Fev. & 4,60 & 6,80 & 34,60 & 66,30 \\
\hline & Mar. & 4,70 & 6,80 & 34,50 & 66,40 \\
\hline & Abr. & 4,50 & 6,70 & 34,00 & 65,30 \\
\hline & Mai. & 4,60 & 6,70 & 33,90 & 65,20 \\
\hline & Jun. & 4,60 & 6,70 & 34,00 & 65,20 \\
\hline & Jul. & 4,60 & 6,60 & 33,80 & 65,40 \\
\hline & Ago. & 4,80 & 6,70 & 34,10 & 65,90 \\
\hline & Set. & 4,80 & 6,80 & 34,50 & 66,70 \\
\hline & Out. & 4,80 & 6,80 & 34,30 & 66,80 \\
\hline & Nov. & 4,80 & 6,90 & 34,80 & 66,70 \\
\hline & Dez. & 5,50 & 7,50 & 36,10 & 67,60 \\
\hline \multirow{12}{*}{2011} & Jan. & 5,10 & 6,80 & 35,40 & 67,10 \\
\hline & Fev. & 4,80 & 6,60 & 35,50 & 67,80 \\
\hline & Mar. & 4,60 & 6,50 & 36,00 & 68,20 \\
\hline & Abr. & 4,40 & 6,30 & 35,80 & 68,00 \\
\hline & Mai. & 4,50 & 6,30 & 36,10 & 68,30 \\
\hline & Jun. & 4,80 & 6,40 & 36,40 & 68,40 \\
\hline & Jul. & 4,50 & 6,30 & 36,70 & 69,20 \\
\hline & Ago. & 4,40 & 6,10 & 37,00 & 70,00 \\
\hline & Set. & 4,60 & 6,30 & 37,60 & 70,70 \\
\hline & Out. & 4,60 & 6,20 & 37,50 & 70,80 \\
\hline & Nov. & 4,40 & 6,30 & 38,10 & 71,50 \\
\hline & Dez. & 5,20 & 6,90 & 39,00 & 73,10 \\
\hline \multirow{5}{*}{2012} & Jan. & 5,10 & 6,20 & 38,30 & 74,20 \\
\hline & Fev. & 4,60 & 6,10 & 38,20 & 74,60 \\
\hline & Mar. & 4,80 & 6,10 & 38,30 & 75,60 \\
\hline & Abr. & 4,60 & 6,10 & 38,00 & 75,90 \\
\hline & Mai. & 4,50 & 6,10 & 38,30 & 76,20 \\
\hline
\end{tabular}

FONTE: Banco Central do Brasil.

NOTA: $\left(^{*}\right)$ base monetária em \% do PIB.

(1) M1- fim de período - \% PIB.

(2) M2 - fim de período - conceito novo - \% PIB.

(3) M3 - fim de período - conceito novo - \% PIB. 
